\title{
Do You Feel in Control? Sexual Desire, Sexual Passion Expression, and Associations with Perceived Compulsivity to Pornography and Pornography Use Frequency
}

\author{
Nathan D. Leonhardt \\ University of Toronto \\ Dean M. Busby \\ Brigham Young University - Provo, dean_busby@byu.edu \\ Brian J. Willoughby \\ Brigham Young University - Provo
}

Follow this and additional works at: https://scholarsarchive.byu.edu/facpub

Part of the Other Social and Behavioral Sciences Commons

\section{Original Publication Citation}

Leonhardt, N. D., Busby, D. M., Willoughby, B. J. (2020). Do You Feel in Control? Sexual Desire, Sexual Passion Expression, and Associations with Perceived Compulsivity to Pornography and Pornography Use Frequency. Sexuality Research and Social Policy.

\section{BYU ScholarsArchive Citation}

Leonhardt, Nathan D.; Busby, Dean M.; and Willoughby, Brian J., "Do You Feel in Control? Sexual Desire, Sexual Passion Expression, and Associations with Perceived Compulsivity to Pornography and Pornography Use Frequency" (2020). Faculty Publications. 4646.

https://scholarsarchive.byu.edu/facpub/4646

This Peer-Reviewed Article is brought to you for free and open access by BYU ScholarsArchive. It has been accepted for inclusion in Faculty Publications by an authorized administrator of BYU ScholarsArchive. For more information, please contact ellen_amatangelo@byu.edu. 


\title{
Do You Feel in Control? Sexual Desire, Sexual Passion Expression, and Associations with Perceived Compulsivity to Pornography and Pornography Use Frequency
}

\author{
Nathan D. Leonhardt ${ }^{1}$ (D) Dean M. Busby ${ }^{2} \cdot$ Brian J. Willoughby $^{2}$ \\ (C) Springer Science+Business Media, LLC, part of Springer Nature 2020
}

\begin{abstract}
Previous scholars have found that when individuals feel that pornography use is uncontrollable, it is linked to more extreme negative outcomes than frequency of use. With a Mechanical Turk sample of 1421 individuals, we used structural equation modeling to evaluate how multiple aspects of sexual desire (sexual drive and dyadic desire) and multiple aspects of sexual passion expression (harmonious, obsessive, and inhibited) were associated with both pornography use frequency and perceived compulsivity to pornography. In general, sexual desire was more connected to pornography use and sexual passion was more connected to perceived compulsivity. Specifically, sexual drive was associated with higher pornography use, whereas both obsessive and inhibited sexual passion were associated with higher perceived compulsivity. The study should help scholars, clinicians, and policy makers to identify factors that can help to overcome potentially problematic pornography use and approach this subject with more nuance.
\end{abstract}

Keywords Pornography $\cdot$ Compulsivity $\cdot$ Sexual desire $\cdot$ Sexual drive $\cdot$ Sexual passion

An estimated $70 \%$ of men and $40 \%$ of women report some pornography ${ }^{1}$ use in the past year (Regnerus, Gordon, \& Price, 2016); yet only an estimated $1-15 \%$ of the population report feeling a lack of control in their use, with the majority of those being men (Cooper, Delmonico, \& Burg, 2000; Cooper, Morahan-Martin, Mathy, \& Maheu, 2002; Grubbs, Kraus, \& Perry, 2019; Sussman, Lisha, \& Griffiths, 2011). Casual pornography (recreational or controlled use) seems to be linked to

\footnotetext{
${ }^{1}$ We recognize that a variety of sexual content may be perceived as pornographic (Willoughby \& Busby, 2016). For the purposes of our study, we define pornography as sexually explicit material intended to arouse the viewer. For a more detailed discussion of how pornography should be defined and measured, see Kohut et al., 2019
}

Nathan D. Leonhardt

nathan.leonhardt@mail.utoronto.ca

Dean M. Busby

dean_busby@byu.edu

Brian J. Willoughby

brian.willoughby@byu.edu

1 Department of Psychology, University of Toronto, Ontario L5L 1C6, Canada

2 School of Family Life, Brigham Young University, Provo, UT 84602, USA a mixture of positive outcomes like "spicing up" the sexual relationship (Olmstead, Negash, Pasley, \& Fincham, 2013), and negative outcomes like objectification of a sexual partner (Leonhardt, Spencer, Butler, \& Theobald, 2019a, Leonhardt, Spencer, Butler, \& Theobald, 2019b; Vandenbosch \& Eggermont, 2012). On the other hand, when individuals report compulsive pornography use, it is linked more consistently with negative outcomes like depression, anxiety, and feeling powerless to stop such use (Butler, Meloy, \& Call, 2015; Grubbs, Stauner, Exline, \& Pargament, 2015). To better understand these negative outcomes, researchers have begun to evaluate how passion expression (Rosenberg \& Kraus, 2014) and desire (Carvalho, Štulhofer, Vieiera, \& Jurin, 2015) in the sexual domain are associated with both frequency of pornography use and perception of compulsion. However, theoretical advancements highlighting multiple aspects of sexual desire (Brotto \& Smith, 2014; Levine, 1987) and sexual passion expression (Busby et al. 2019a, b) are yet to be tested in how they may uniquely predict both frequency of use and perceived compulsivity to pornography. The manner in which someone expresses their sexuality likely influences the manner in which pornography is used.

Due to the use of many constructs that are complex, and in some cases novel, the first portion of our literature review explains these constructs. First, we define and explain the 
importance of considering multiple aspects of pornography use (frequency of use and perceived compulsivity). Second, we define and explain the importance of multiple aspects of sexual desire (sexual drive and dyadic desire). Third, we define and explain the importance of considering multiple aspects of sexual passion expression (harmonious, obsessive, inhibited). Finally, we integrate each of these bodies of literature by hypothesizing how multiple aspects of sexual desire and sexual passion expression may be associated with both pornography use frequency and perceived compulsivity to pornography. Overall, the purpose of this study was to assess how multiple aspects of sexual desire (sexual drive and dyadic desire) and multiple aspects of sexual passion expression (harmonious, obsessive, and inhibited) are associated with both pornography use and perceived compulsivity to pornography. By better understanding how each of these constructs is associated with each other, we can begin to better parcel out who feels their pornography use is out of control, as opposed to who feels they use pornography without the constraint of compulsion.

\section{Pornography}

Research on pornography compulsion sometimes focuses on objective behavior, such as more than $11 \mathrm{~h}$ of viewing pornography in a week (Cooper, Scherer, Boies, \& Gordon, 1999). Recent research has also focused on the subjective experience of compulsion in addition to objective criteria. Additional focus on the subjective element of compulsion seems appropriate, as it has been shown to predict negative individual (Grubbs, Stauner, Exline, \& Pargament, 2015) and relational outcomes (Leonhardt, Willoughby, \& YoungPetersen, 2018) above and beyond frequency of pornography use. This subjective element of perceived compulsivity has been conceptualized as the amount of control individuals feel over their pornography use, irrespective of how frequently they use pornography (Grubbs, Exline, Pargament, Hook, \& Carlisle, 2015). Casual pornography may be conceptualized as the inverse, the frequency of use irrespective of feelings of control. Previous research has highlighted the importance of parceling out frequency of pornography use and perceived compulsivity, as some pornography users report relatively frequent use, yet report low compulsivity (Gola, Lewczuk, \& Skorko, 2016), yet others report relatively infrequent use, but high compulsivity (Grubbs, Exline, Pargament, Hook, \& Carlisle, 2015).

An ongoing debate exists in the current literature as to whether someone's reported level of compulsion (irrespective of use) accurately reflects a real compulsion, or is an element of cognitive dissonance inaccurately assessing the nature of behavior (for articles attempting to better parcel out these issues, see Fernandez, Tee, \& Fernandez, 2017; Grubbs,
Stauner, Exline, \& Pargament, 2015, Grubbs \& Perry, 2019). Our particular study does not try to resolve this debate. Rather, we recognize that someone's perceived level of compulsivity (which may or may not be indicative of an actual compulsion) has been shown to predict negative outcomes above and beyond frequency of use. For that reason, understanding how this perception is developed is important amidst ongoing research attempting to better understand the extent that this perceived compulsion is indicative of an actual compulsion. Desire (Carvalho et al., 2015; Prause \& Pfaus, 2015) and passion expression (Rosenberg \& Kraus, 2014) in the sexual domain are factors worthy of attention.

\section{Sexual Desire and Sexual Passion}

Sexual Desire Sexual desire was originally considered primarily a biological and physiological function (Beach, 1956; Masters \& Johnson, 1966), comprising hormonal mechanisms such as dopamine (Pfaus, 2009), norepinephrine (Meston, Gorzalka, \& Wright, 1997), and oxytocin (MacDonald \& Feifel, 2012). More recently, research has also suggested that sexual desire is formed from psychological and social factors, such as negative sexual beliefs (Nobre, 2009), mindfulness (Brotto, Basson, \& Luria, 2008), sexual scripts (McCarthy \& McDonald, 2009), education (Laumann, Paik, \& Rosen, 1999), and relational context (Basson, 2001, 2003). Although the field continues to debate overarching components of sexual desire, Levine (e.g., 1987, 2003) has contributed to the growing consensus that sexual desire is multifaceted (Brotto \& Smith, 2014).

Due to the multifaceted nature of sexual desire, we operationalized sexual drive as more general interest in sexual activity, perhaps tapping into an underlying biological drive. Meanwhile, we operationalized dyadic sexual desire, as sexual desire specifically directed toward a partner, thus capturing more of the relational focus of sexual interest. To this point, little empirical investigation has evaluated distinction of these constructs, but recent research has empirically supported the notion that they are unique constructs and vary in their associations with sexual outcomes (Busby et al., 2019a).

Sexual Passion Expression Although sexual desire and sexual passion expression have some overlap, they have distinct predictive validity (Busby et al., 2019a; Philippe, Vallerand, Bernard-Desrosiers, Guilbault, Rojotte, 2017). Sexual desire is moderately correlated with sexual passion expression (Philippe et al., 2017), but sexual passion expression tends to have more nuance in its formation. While sexual desire is focused more on the extent someone has an interest in sexuality, sexual passion expression is more focused on how that sexual interest is internalized and controlled. 
Once conceived as a unidimensional phenomenon (Hatfield \& Rapson, 1990; Sternberg, 1986), passion research has evolved into a dualistic (Phillippe, Vallerand, BernardDesrosiers, Guilbault, \& Rojotte, 2017; Vallerand et al., 2003) and most recently a triadic model of sexual passion expression (Busby et al., 2019a). The triadic model of sexual passion argues that sexual passion expression is comprised of an adaptive, autonomously controlled (1) harmonious sexual passion, and two maladaptations of control: an undercontrolled (2) obsessive sexual passion, and a newly conceptualized overcontrolled (3) inhibited sexual passion. In more detail, harmonious sexual passion constitutes balanced, autonomous, controlled engagement in sexual activity, which has been connected to positive outcomes (Philippe et al., 2017). Obsessive sexual passion is an undercontrolled expression of passion, basically an intense, underregulated urge to engage in sexual activity. Inhibited sexual passion likely comes from the combination of wanting to participate in sexual activity while simultaneously feeling moral or social constraints from expressing sexual passion (overregulation).

Factor analyses have shown that the three constructs are unique and have sound psychometric properties. One study found that harmonious sexual passion was strongly, positively correlated with sexual satisfaction and relationship satisfaction; inhibited sexual passion was negatively correlated with both outcomes; obsessive sexual passion had limited correlation with either sexual or relationship satisfaction. Though interestingly, obsessive sexual passion was positively linked to both harmonious and inhibited sexual passion (Busby et al., 2019a).

\section{Current Study}

The purpose of this study was to assess whether multiple aspects of sexual desire (sexual drive and dyadic desire) and sexual passion expression (harmonious, obsessive, and inhibited) were uniquely associated with both frequency of pornography use and perceived compulsivity to pornography. Pornography is intertwined with sexuality, yet is often studied in isolation of someone's broader sexual context. Assessing multiple dimensions of sexual desire and sexual passion simultaneously can be a helpful component to parceling out their connections to both frequency of pornography use and perceived pornography compulsion. This is because each of these five predictors has a combination of both conceptual and statistical distinction and overlap (Busby et al., 2019a). This means that if any of these constructs were to be omitted from the analysis, scholars could misattribute one variable to be associated with an outcome, when another variable is actually responsible. A more complete understanding of how someone manages their sexual desire and sexual passion expression may help us better understand what factors lead to pornography use being more problematic.

With all variables evaluated simultaneously, we broadly hypothesized (H1) that the sexual desire variables (sexual drive and dyadic desire) would be more strongly associated with pornography use frequency and that the sexual passion variables (harmonious, obsessive, and inhibited) would be more strongly associated with perceived compulsivity to pornography. As mentioned, the likely reason for this distinction is that the sexual passion variables are specifically operationalized around the idea of adaptive or maladaptive expression of sexuality (Busby et al., 2019a; Philippe et al., 2017). On the other hand, debate exists in the field concerning the role of sexual desire and sexual compulsivity (with compulsive pornography use often considered a subcomponent). Some researchers have described sexual desire and sexual compulsivity as being closely linked that they may not be distinguishable (Steele, Staley, Fong, \& Prause, 2013), while others have suggested clearer conceptual and statistical distinction (Carvalho et al., 2015). Interestingly, Carvalho et al. (2015) found that desire seems more linked with pornography use, irrespective of feelings of control. The combined evidence suggests that while someone with high sexual desire may feel difficulty controlling pornography use, a desire for frequent pornography use can also feel undercontrol (Carvalho et al., 2015; Steele et al., 2013).

Additionally, we hypothesized (H2) that sexual drive would be associated with higher pornography use, and dyadic sexual desire would lose significant association with pornography use when evaluated with the other variables. Multiple studies have suggested that pornography use is positively associated with sexual desire (Prause \& Pfaus, 2015; Steele et al., 2013). Yet, limited research has parceled out associations between multiple aspects of sexual desire and pornography use, which may result in neglecting important nuance between the associations. For assessing sexual desire and pornography variables, it is important to consider that typical pornographic content focuses more on sexual pleasure than the relational element of sexuality (e.g., Bridges, Wosnitzer, Scharrer, Sun, \& Liberman, 2010; Leonhardt et al., 2019a), and that individuals are more likely to search out media content with which they identify (Katz, Blumler, \& Gurevitch, 1974). For that reason, individuals who have higher sexual drive, rather than relationally focused sexual desire toward a partner, may be more likely to seek out pornography. Specifically, considering that a general sexual drive and sexual desire toward a partner are positively correlated with each other (Busby et al., 2019a), if the two factors are taken into account simultaneously, the more general sexual drive seems more likely to be associated with pornography use than dyadic desire specifically directed at a partner.

We also hypothesized (H3a) that both obsessive and inhibited sexual passion would be associated with higher 
perception of compulsive pornography use. The link between obsessive sexual passion and perceived compulsivity seems intuitive, as the idea of undercontrol lines up with previous research suggesting that general obsessive passion can be a precursor to addiction (Lafreniere, Jowett, Vallerand, Donahue, \& Lorimer, 2008). One study specifically showed that obsessive passion toward pornography was linked to sexual compulsivity (Rosenberg \& Kraus, 2014). Hypothesizing the positive link between inhibited sexual passion and perceived compulsivity seems less intuitive, as some may wonder whether inhibited sexual passion may present an aversion to sexuality in general. Important to understand is that inhibited sexual passion, like obsessive sexual passion, taps into the overall understanding of maladaptive control. In fact, Busby et al. (2019a) provided evidence for this idea by showing that obsessive and inhibited sexual passion are positively correlated with each other, suggesting the possibility that those with maladaptive control may rotate between obsessive and inhibited expression of sexual passion. Maladaptive control of sexuality at either extreme may suggest feeling difficulty controlling pornography use, irrespective of how often someone actually uses pornography.

Finally, we hypothesized (H3b) that harmonious sexual passion would be associated with lower perceived compulsive pornography use, as harmonious sexual passion reflects autonomous control of sexual passion. At first glance, a hypothesized negative association between harmonious sexual passion and perceived compulsivity seems counter to previous research showing that harmonious passion directed at pornography is associated with higher pornography use (Rosenberg $\&$ Kraus, 2014). Although Rosenberg and Kraus (2014) provided important insight for links between pornography use, passion, and compulsivity, their study focused on passion toward pornography, and did not consider a more general sexual passion in a committed relationship. Our study has done the inverse, focusing on a more general sexual passion in a committed relationship, and the resulting compulsivity surrounding pornography use. Although harmonious passion focused toward pornography may be connected with higher pornography use (Rosenberg \& Kraus, 2014), harmonious sexual passion in a committed relationship may actually be a buffer against compulsive pornography use because it implies an overarching autonomous control of the sexuality.

Although gender is not a major focus of the study, it is important to consider as studies have suggested some differences between how women and men perceive pornography (Leonhardt \& Willoughby, 2019; Willoughby \& Busby, 2016). Additionally, gender differences exist in evaluation of sexual desire (Brotto \& Smith, 2014), sexual passion expression (Busby et al., 2019a), and pornography consumption (Carroll et al., 2008). We therefore asked the broad question (RQ1) "are these results consistent between men and women?"

\section{Method}

\section{Sample and Procedure}

The sample of the present study consisted of 1421 individuals in a committed romantic relationship (649 male, 772 female). The sample came from the Amazon Mechanical Turk (MTurk) website (http://www.mturk.com), for a study focused more broadly on the expression of sexual passion in committed relationships. All of the participants reported being a US citizen. MTurk is a website dedicated to online labor and is used to employ "workers" from around the world to complete specific tasks. In regard to the current project, a job was posted inviting participants to complete a short 10 to 15 -min survey on sexuality and passion in a relationship. Participants were instructed that they needed to be English speaking, and those who were interested were directed to a separate website to complete an online assessment. Sexual orientation was not an exclusionary criterion, but we only ended up with $2.4 \%$ of our sample who reported a same-sex orientation, limiting our ability to explore this matter. Before beginning the online survey, participants were asked to indicate informed consent and were informed about their rights as a research participant. The codebook listing all of our measures in the dataset is available on the Open Science Framework (https://osf.io/8rewd/). Output from our analyses is also available (https://osf.io/7esrj/).

Upon completion of the survey, participants were given compensation of $\$ 0.50$, a rate similar to comparable tasks on the MTurk website. Scholars have noted that samples from MTurk are very similar to other diverse behavioral research samples, and several scholars have replicated previous research results on MTurk to provide evidence for the validity of the sample (Paolacci, Chandler, \& Ipeirotis, 2010; Suri \& Watts, 2011). MTurk was an appropriate avenue for our study as it has credibility for early exploration of newly developed constructs (Buhrmester, Talaifar, \& Gosling, 2018). At the same time, some concerns have arisen about the quality of data from MTurk studies (Chmielewski \& Kucker, 2019). The sample originally had 1629 individuals, but to ensure quality data, 208 participants were removed who missed one of the attention check questions (e.g., If you are reading this closely, please select "Strongly Agree"). We also decreased the likelihood of bots or duplicate data by checking for patterns in IP addresses and GPS coordinates (Bai, 2018). Furthermore, the data were collected in 2016, before major concerns about bots.

The participants ranged in age from 18 to 83 with the mean age of the sample being 34.12 years $(\mathrm{SD}=10.46)$. Seventy-six percent of the sample was White, 7.4\% were Black, 5.4\% were Asian, and $4.9 \%$ were Latino. Participants also reported a variety of religious affiliations: $27.0 \%$ reported Protestant, 19.3\% reported Catholic, $2.3 \%$ reported Hindu, $2.0 \%$ reported Jewish, $1.7 \%$ reported Buddhist, and $32.5 \%$ reported no 
religious affiliation. Eleven percent reported an "other" religious affiliation.

For relationship status, $44.2 \%$ of participants reported "Exclusively dating someone," $7.4 \%$ reported being "Engaged," and 48.7\% reported being "Married." The length that participants had been in a relationship ranged from 1 to 603 months with the mean length of relationship being 82.49 months $(\mathrm{SD}=91.56)$. For education and income, $28.6 \%$ of the sample reported completing a high school education or less, and the remaining $71.4 \%$ reported receiving some kind of degree, with $13.2 \%$ of the sample receiving an advanced degree. The majority of the sample reported an income between $\$ 20,000$ and $\$ 100,000$ (67.3\%), while $24.3 \%$ reported an income under $\$ 20,000$, and $7.8 \%$ reported an income above $\$ 100,000$.

\section{Measures}

Specific items of interest are included in Table 3.

Pornography Pornography use was measured as a latent construct derived from a study by Busby, Willoughby, Chiu, and Olsen (2020). The five items used for pornography use were some of those most agreed upon by the sample to be pornographic content (for a detailed description of how items were created and validated, see Willoughby \& Busby, 2016 \& Busby et al., 2020) and would be considered to be more mainstream content (Leonhardt et al., 2019a). In the questionnaire, participants read depictions of several types of pornographic content. The variables were measured with a six-point Likert scale ( $1=$ none; $6=$ every day or almost every day) measuring how often in the last 12 months participants had viewed or used the sexual content (i.e., an image of a heterosexual couple having sex which shows the man's penis penetrating the woman). The lowest factor loadings were .75 for males and .78 for females, and the reliability was acceptable for both men $(\alpha=.86)$, and women $(\alpha=.85)$. Perception of compulsion was assessed as a latent variable forming the Perception of Compulsion subscale from the Perception of Pornography Addiction Scale (Grubbs, Exline, \& Pargament, 2015). The variables were measured with a seven-point Likert scale $(1=$ not at all; 7 = extremely). One sample item was "I feel unable to stop my use of pornography." The lowest factor loadings were .89 for men and .83 for women and the reliability was acceptable for both men $(\alpha=.93)$ and women $(\alpha=.90)$

Sexual Desire Two aspects of sexual desire were assessed, each with a single item. Dyadic sexual desire was assessed with one item on a seven-point Likert scale "How often do you desire to have sexual intercourse with your partner?" $(1=$ never; $7=$ more than once a day). The more general sexual drive was also assessed with one item, but on a six-point Likert scale "During the past 30 days, on how many days have you felt sexual drive?
Sexual drive is defined as wanting to have sexual experience, thinking about having sex, or feeling frustrated due to lack of sex." $(1=$ no days; $6=$ several times a day $)$.

Sexual Passion Three distinct constructs developed by Busby et al. (2019a) were assessed on a five-point Likert scale ( $1=$ never; $5=$ very often): harmonious sexual passion, obsessive sexual passion, and inhibited sexual passion. Five items were used to form a latent variable for harmonious sexual passion. One example item was "Excitement about sexual activities with my partner is balanced with the rest of my life." The lowest factor loading for harmonious sexual passion was .45 for men and .54 for women, and the reliability was acceptable for men $(\alpha=.84)$ and women $(\alpha=.86)$. Six items were used to form a latent variable for obsessive sexual passion. One example item was "I am easily controlled by my strong sexual interests with my partner." The lowest factor loading for obsessive sexual passion was .54 for men and .58 for women, and the reliability was acceptable for men $(\alpha=.85)$ and women $(\alpha=.87)$. Finally, five items were used to form a latent variable for inhibited sexual passion. One example item was "I often feel reluctant to act on sexual urges that I have for my partner." The lowest factor loading for inhibited sexual passion was .61 for men and .62 for women, and the reliability was acceptable for men $(\alpha=.78)$ and women $(\alpha=.78)$.

Control Variables Emotional regulation (Leonhardt \& Willoughby, 2019; Wetterneck, Burgess, Short, Smith, \& Cervantes, 2012), shyness (Luster, Nelson, Poulsen, \& Willoughby, 2013), religiosity (Grubbs, Exline, Pargament, Hook, \& Carlisle, 2015; Leonhardt et al., 2018), and relationship length (Klusmann, 2002) were all entered as controls, as previous research suggests they each have the potential to confound associations between sexual desire, sexual passion, and pornography outcomes. Emotional regulation was assessed as a latent construct formed from five items from the Emotional Self-Regulation scale (Novak \& Clayton, 2001). The scale was a four-point Likert scale ( $1=$ never true; $4=$ always true) with one example item being "Often I am afraid I will lose control over my feelings." The lowest factor loading was .65 for men and .63 for women, and reliability was acceptable for men $(\alpha=.87)$ and women $(\alpha=.86)$. Shyness was assessed on a five-point Likert scale $(1=$ strongly disagree; $5=$ strongly agree) with five items from the Child Social Preference scale (Coplan, Prakash, O’Neil, \& Armer, 2004) that had been adapted for adults (Luster et al., 2013). One example was "I'd like to hang out with other people, but I'm sometimes nervous to." The lowest factor loading for men was .81 and for women was .83 , and the reliability was also acceptable for men $(\alpha=.93)$, and women $(\alpha=.94)$. Religiosity was also assessed through three variables from the RELATE questionnaire (Busby, Holman, \& Taniguchi, 2001) that formed a latent variable. One example item was 
"Spirituality is an important part of my life" ( $1=$ never; $5=$ very often). The lowest factor loading for religiosity was .71 for men and .69 for women, and the reliability was acceptable for men $(\alpha=.87)$ and women $(\alpha=.88)$.

\section{Data Analysis Plan}

To get a sense of the overall patterns within the data, we first ran a MANOVA to assess differences across gender (Table 1). Because there were significant gender differences, we then assessed the bivariate associations between the variables of interest for each gender and created a correlation matrix that was separated by gender (Table 2).

Before estimating the full structural model, we first tested for measurement invariance to see whether it would be appropriate to conduct multi-group analysis. We found that the pornography variables and obsessive sexual passion had no level of invariance. Furthermore, harmonious and inhibited sexual passion only reached weak invariance (full results available at https:// osf.io/7esrj/). Considering the lack of measurement invariance, we decided that it would be most appropriate to run separate models for each gender rather than grouping them together to make direct comparisons through a multi-group model.

We first assessed the measurement of our latent variables through measurement models for both men and women (see Table 3 for factor loadings). After ensuring appropriate measurement, we estimated separate structural equation model analyses for men and women, and assessed how sexual passion, sexual desire, personality characteristics, and religiosity were associated with both pornography use frequency and perception of pornography compulsion when considered simultaneously. This evaluation allowed us to control for the shared variance among the constructs and explore unique associations for each dimension with the predictor variables. Models in Fig. 1 were estimated with robust maximum likelihood (MLR) with the MPlus version 8.4 (Muthen and Muthen 1998-2012). Although error terms were included for each of the endogenous variables listed in the structural equation model, in order to simplify the figure, they were not drawn into Fig. 1. Kline (2016) recommends 10 observations for every manifest variable. With 40 manifest variables in our most complicated models of 649 men and 772 women, we met the suggested number of observations for power. We did not conduct power analyses a priori as this is a larger project focused on sexuality and passion, and the questions for this specific study were developed after the data were collected.

We also estimated a series of alternative models for both women and men. One alternative having pornography use and perception of compulsion predict the three types of passion and two types of sexual desire; the second was to have pornography use, perception of compulsion, and the two types of sexual desire predict the three types of sexual passion expression; the third was to have pornography use, perception of compulsion, and the three types of sexual passion predict the two types of sexual desire. Model fit was identical across all models (see https://osf.io/7esrj/ for full results).

\section{Results}

\section{Descriptive Statistics}

Gender differences were explored for all the variables. A multivariate analysis of variance (MANOVA) revealed an overall

Table 1 Descriptive statistics and gender differences

\begin{tabular}{|c|c|c|c|c|c|c|c|}
\hline \multirow[b]{2}{*}{ Variable } & \multicolumn{2}{|c|}{ Male $(N=649)$} & \multicolumn{2}{|c|}{ Female $(N=772)$} & \multirow[t]{2}{*}{ Response range } & \multirow[b]{2}{*}{ Cohen's d } & \multirow[b]{2}{*}{$F$ value } \\
\hline & $M$ & $S D$ & $M$ & $S D$ & & & \\
\hline Religiosity & 2.63 & 1.26 & 2.81 & 1.31 & $1-5$ & .14 & $6.66^{* *}$ \\
\hline Emotional regulation & 1.67 & .62 & 1.83 & .64 & $1-4$ & .25 & $21.38 * * *$ \\
\hline Shyness & 2.79 & 1.18 & 3.13 & 1.23 & $1-5$ & .28 & $27.50 * * *$ \\
\hline Dyadic desire & 4.91 & 1.27 & 4.68 & 1.23 & $1-7$ & .18 & $11.33 * *$ \\
\hline Sexual drive & 4.21 & 1.25 & 3.55 & 1.19 & $1-6$ & .54 & $102.46^{* * *}$ \\
\hline Harmonious sexual passion & 3.51 & .78 & 3.58 & .83 & $1-5$ & .09 & 2.57 \\
\hline Obsessive sexual passion & 2.41 & .80 & 2.10 & .80 & $1-5$ & .39 & $56.11 * * *$ \\
\hline Inhibited sexual passion & 2.23 & .78 & 2.28 & .82 & $1-5$ & .06 & 1.04 \\
\hline Pornography use & 2.82 & 1.37 & 1.70 & .89 & $1-6$ & .97 & $358.95 * * *$ \\
\hline Perception of compulsion & 2.43 & 1.63 & 1.29 & .82 & $1-7$ & .88 & $291.93 * * *$ \\
\hline Relationship length & 82.16 & 94.53 & 82.77 & 89.06 & $1-603$ & .01 & .015 \\
\hline
\end{tabular}

\footnotetext{
* $p<.05$

*** $p<.01$

**** $p<.001$
} 
Table 2 Bivariate correlations for all variables

\begin{tabular}{|c|c|c|c|c|c|c|c|c|c|c|c|c|}
\hline & Variable & 1 & 2 & 3 & 4 & 5 & 6 & 7 & 8 & 9 & 10 & 11 \\
\hline 1. & Religiosity & -- & -.02 & -.02 & -.02 & -.04 & $.08 *$ & .02 & .06 & $-.20 * * *$ & .03 & $.16^{* * *}$ \\
\hline 2. & Emotional regulation & -.02 & -- & $.28 * * *$ & -.01 & .03 & $-.17 * * *$ & $.23 * * *$ & $.30 * * *$ & $.17 * * *$ & $.21 * * *$ & -.06 \\
\hline 3. & Shyness & -.06 & $.30 * * *$ & -- & $-.08^{*}$ & -.04 & $-.19 * * *$ & .04 & $.34 * * *$ & $.12 * *$ & $.08 *$ & -.03 \\
\hline 4. & Dyadic desire & -.07 & .02 & $-.08^{*}$ & -- & $.60 * * *$ & $.36 * * *$ & $.29 * * *$ & $-.30 * * *$ & $.18 * * *$ & $.07 *$ & $-.29 * * *$ \\
\hline 5. & Sexual drive & $-.14 * * *$ & .05 & -.01 & $.37 * * *$ & -- & $.30 * * *$ & $.30 * * *$ & $-.28 * * *$ & $.24 * * *$ & .04 & $-.21 * * *$ \\
\hline 6. & Harmonious sexual passion & $.10^{*}$ & $-.17 * * *$ & $-.28 * * *$ & $.33 * * *$ & .06 & -- & $.17 * * *$ & $-.50 * * *$ & .06 & $-.09 *$ & $-.17 * * *$ \\
\hline 7. & Obsessive sexual passion & $.15 * * *$ & $.28 * * *$ & $.13^{* *}$ & $.21 * * *$ & $.14 * * *$ & $.12 * *$ & -- & $.15^{* * *}$ & $.24 * * *$ & $.25 * * *$ & $-.20 * * *$ \\
\hline 8. & Inhibited sexual passion & $.13 * *$ & $.34 * * *$ & $.33 * * *$ & $-.18 * * *$ & $-.10^{*}$ & $-.35 * * *$ & $.36^{* * *}$ & -- & .06 & $.23 * * *$ & $.08 *$ \\
\hline 9. & Pornography use & $-.20 * * *$ & $.11 * *$ & $.10^{*}$ & $.12 * *$ & $.35 * * *$ & .06 & $.12 * *$ & .06 & -- & $.42 * * *$ & $-.21 * * *$ \\
\hline 10. & Perception of compulsion & -.00 & $.30 * * *$ & $.24 * * *$ & $-.09 *$ & $.12 * *$ & $-.24 * * *$ & $.27 * * *$ & $.34 * * *$ & $.36 * * *$ & -- & -.03 \\
\hline 11. & Relationship length & .04 & $-.08^{*}$ & -.04 & $-.23 * * *$ & $-.11 * *$ & $-.13 * *$ & $-.17 * * *$ & -.06 & $-.15 * * *$ & -.07 & -- \\
\hline
\end{tabular}

Men's correlations are below the dashes. Women's correlations are above the dashes

${ }^{*} p<.05$

${ }^{* *} p<.01$

**** $p<.001$

Table 3 Factor loadings for independent and dependent latent variables

\begin{tabular}{|c|c|c|}
\hline Items & Men & Women \\
\hline \multicolumn{3}{|l|}{ Pornography use } \\
\hline $\begin{array}{l}\text { An image of a heterosexual couple having sex which shows the man's penis penetrating the } \\
\text { woman. }\end{array}$ & .71 & .75 \\
\hline A video showing two naked women or men kissing each other. & .91 & .90 \\
\hline A video showing two naked women or men manually stimulating each other. & .93 & .92 \\
\hline A video of a woman or man alone masturbating. & .79 & .76 \\
\hline A video that graphically depicts a three-way sexual encounter. & .78 & .79 \\
\hline \multicolumn{3}{|l|}{ Perceived compulsivity } \\
\hline I believe I am addicted to pornography. & .91 & .92 \\
\hline Even when I do not want to use pornography, I feel drawn to it. & .90 & .83 \\
\hline I feel unable to stop my use of pornography. & .89 & .88 \\
\hline \multicolumn{3}{|l|}{ Harmonious sexual passion } \\
\hline I appreciate and seek new sexual experiences with my partner & .46 & .55 \\
\hline $\begin{array}{l}\text { The way I live my life allows me to have a variety of sexual experiences which I desire with my } \\
\text { partner. }\end{array}$ & .79 & .79 \\
\hline My sexual interests are well integrated into my relationship with my partner. & .86 & .85 \\
\hline $\begin{array}{l}\text { The sexual activities that I am excited about in my relationship with my partner are in harmony } \\
\text { with the other things that are a part of me. }\end{array}$ & .72 & .78 \\
\hline Excitement about sexual activities with my partner is balanced with the rest of my life. & .74 & .76 \\
\hline \multicolumn{3}{|l|}{ Obsessive sexual passion } \\
\hline Generally, I have difficulties controlling any sexual impulses with my partner. & .55 & .58 \\
\hline $\begin{array}{l}\text { I get so involved in my sexual interests with my partner that they consume all my time and } \\
\text { energy. }\end{array}$ & .75 & .75 \\
\hline I am completely consumed by my sexual interests involving my partner. & .75 & .79 \\
\hline $\begin{array}{l}\text { My intense emotions about sexual things, in my relationship with my partner, take complete } \\
\text { control over me. }\end{array}$ & .76 & .77 \\
\hline I am easily controlled by my strong sexual interests with my partner. & .68 & .76 \\
\hline I can easily get obsessed about sexual activities with my partner. & .68 & .77 \\
\hline \multicolumn{3}{|l|}{ Inhibited sexual passion } \\
\hline I often feel reluctant to act on sexual urges that I have for my partner. & .66 & .65 \\
\hline $\begin{array}{l}\text { I am hesitant to participate in various sexual opportunities presented to me in my relationship with } \\
\text { my partner. }\end{array}$ & 64 & 66 \\
\hline $\begin{array}{l}\text { Sometimes, I have so many worries that I feel constrained from doing sexual activities I enjoy } \\
\text { with my partner. }\end{array}$ & .66 & .67 \\
\hline $\begin{array}{l}\text { Unless things are perfect in my relationship with my partner, I am reluctant to participate in sexual } \\
\text { activities. }\end{array}$ & .67 & .64 \\
\hline Generally, I feel inhibited in doing sexual acts with my partner that I am interested in. & .60 & .61 \\
\hline
\end{tabular}




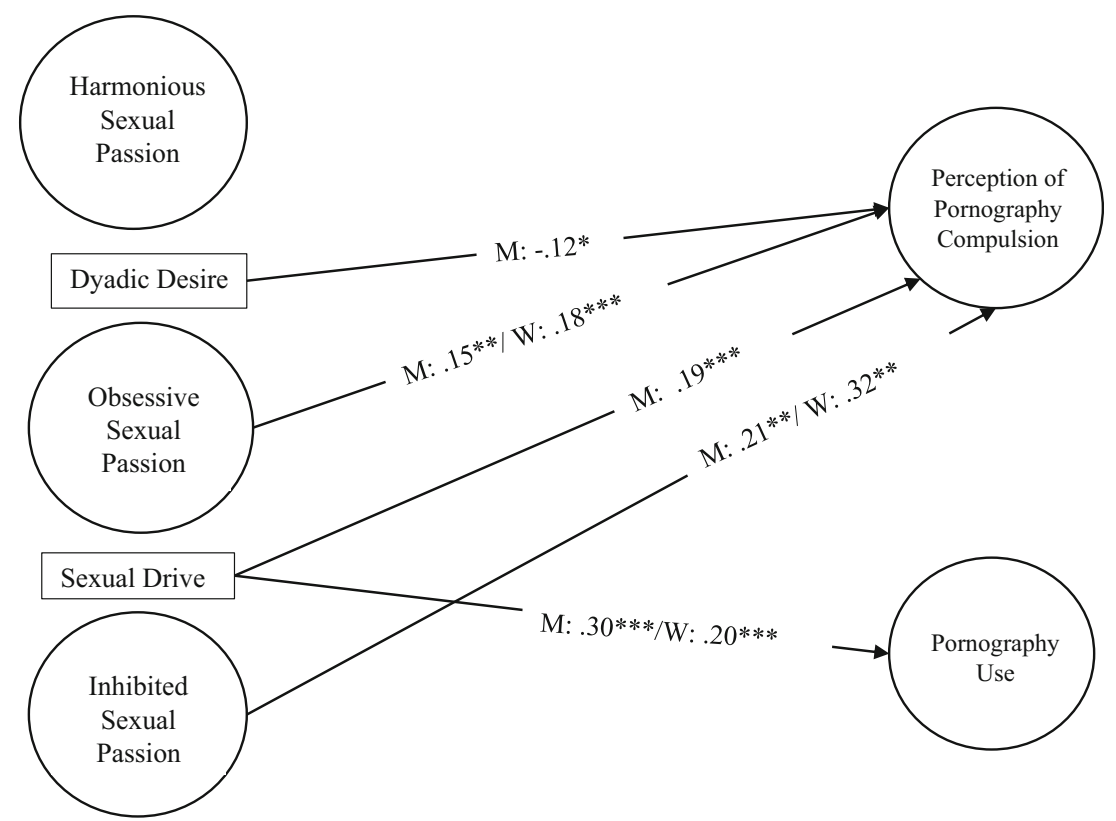

Fig. 1 Structural equation model for how sexual desire and sexual passion are associated with pornography use and perception of compulsion. Men, $\chi^{2}(688)=1344.02, p<.001$, CFI $=.95$, $\mathrm{RMSEA}=.04, \mathrm{SRMR}=.05$. Women, $\chi^{2}(686)=1422.86, p<.001$, $\mathrm{CFI}=.95$, RMSEA $=.04, \mathrm{SRMR}=.04$. Omitted from the figure for

significant gender difference, $F(10,1406)=75.46, p<.001$, partial eta-square $=.35$. Levene's test was non-significant for all variables except pornography use and perception of compulsion $(p<.001)$. Accordingly, group comparisons for both pornography constructs should be viewed with some caution. Table 1 shows means, standard deviations, and $F$ values for each variable. Univariate tests for each variable revealed significant gender differences for all variables (ranging from $p<.01$ to $p<.001$ ), with the exception of harmonious $(p=.10)$ and inhibited sexual passion $(p=.28)$. Specifically, men reported lower religiosity $(p<.01)$, emotional regulation $(p<.001)$, and shyness $(p<.001)$, but higher dyadic sexual desire $(p<.01)$, sexual drive $(p<.001)$, pornography use $(p<.001)$, and perception of compulsion $(p<.001)$. Though it should be noted that this is a large sample size, so small differences should be treated with caution (e.g., the small Cohen $\mathrm{d}$ for religiosity).

\section{Bivariate Associations}

Because of extensive gender differences between the variables, bivariate correlations were run for both males and females to preliminarily assess associations between variables of interest. For parsimony, we do not report all the significant correlations (see Table 2 for full results), but we note several of the most important findings from the correlations. As hypothesized, the sexual passion variables were more consistently associated with perceived compulsion than actual pornography use. Also, both sexual drive and dyadic sexual desire parsimony are non-significant paths and latent variable and endogenous error correlations. Analyses controlled for relationship length, emotional regulation, shyness, and religiosity. All values represent standardized beta weights. The beta weight before the slash represents associations for men, after the slash for women. $* p<.05, * * p<.01, * * * p<.001$

were associated with higher pornography use for both men and women, but much less consistency across gender was found for associations between the sexual desire items and perceived compulsivity. Once again, due to the large sample size, we caution against overinterpreting small significant coefficients.

\section{Structural Equation Model}

Measurement Models Measurement models were first conducted to assess the latent constructs. The final measurement models fit the data adequately (men, $\chi^{2}(601)=1169.62$, $\mathrm{CFI}=.95$, RMSEA $=.04$, SRMR $=.05$; women, $\chi^{2}(601)=$ $1281.76, \mathrm{CFI}=.95$, RMSEA $=.04, \mathrm{SRMR}=.05)$. All factor loadings were above .45 for both genders (see Table 3 for factor loadings of main independent and dependent variables).

Structural Models In order to account for the shared variance between these interrelated factors, we then used separate structural equation models to simultaneously evaluate associations between all variables of interest for both men and women. The model fits were acceptable (Browne \& Cudeck, 1993) for both genders (men, $\chi^{2}(688)=1344.02, p<.001$ $\mathrm{CFI}=.95$, RMSEA $=.04$, SRMR $=.05$; women, $\chi^{2}(688)=$ $1442.86, p<.001 \mathrm{CFI}=.95$, RMSEA $=.04$, SRMR $=.04$ ), and explained moderate variance of the constructs for both men and women: men pornography use $\left(R^{2}=.18\right)$, men perception of compulsion $\left(R^{2}=.30\right)$, women pornography use $\left(R^{2}=.18\right)$, women perception of compulsion $\left(R^{2}=.16\right)$. 
For both men and women, sexual drive was significantly associated with higher pornography use (men, $\beta=.30$, $p<.001$; women, $\beta=.20, p<.001$ ), but was only associated with higher perception of compulsion for men (men, $\beta=.19$, $p<.001$; women, $\beta=-.01, p=.88$ ). Alternatively, dyadic sexual desire was not associated with pornography use for either gender (men, $\beta=-.03, p=.62$; women, $\beta=.02$, $p=.77$ ), yet was associated with lower perception of compulsion for men $(\beta=-.12, p=.01)$, and not associated with perception of compulsion for women $(\beta=.09, p=.05)$.

For both men and women, obsessive sexual passion was associated with higher perceived compulsion (men, $\beta=.15$, $p<.01$; women, $\beta=.18, p<.001$ ), but was not associated with higher pornography use (men, $\beta=.08, p=.20$; women, $\beta=.10, p=.06$ ). Inhibited sexual passion followed a similar pattern, as it was associated with higher perceived compulsivity for both genders (men, $\beta=.21, p<.01$; women, $\beta=.32$, $p<.01$ ), yet was not associated with pornography use frequency for either gender (men, $\beta=.01, p=.88$; women, $\beta=.16, p=.06$ ). Finally, harmonious sexual passion was not associated with perception of compulsion (men, $\beta=-.09$, $p=.16$; women, $\beta=.05, p=58$ ) or pornography use frequency (men, $\beta=-.08, p=.16$; women, $\beta=.08, p=.21$ ) for either gender.

Multiple control variables also had significant associations with the outcomes. For both genders, religiosity (men, $\beta=$ $-.17, p<.001$; women, $\beta=-.20, p<.001)$ and relationship length (men, $\beta=-.11, p<.01$; women, $\beta=-.11, p<.001$ ) were associated with lower pornography use. Emotional regulation was associated with higher perception of compulsion for men $(\beta=.23, p<.001)$.

\section{Discussion}

In this study, we explored how sexual desire and sexual passion expression may differ in their associations between pornography use frequency and perceived compulsion to pornography. We hypothesized (H1) that sexual desire would be more important for use frequency while sexual passion expression would be more important for perceived compulsivity. Our main hypothesis was generally supported, as the sexual desire variables were more strongly associated with pornography use and the sexual passion variables were more strongly associated with perceived compulsivity. One possible reason for this distinction is that the sexual passion variables were specifically operationalized around the idea of adaptive or maladaptive control of sexuality (Busby et al., 2019a; Philippe et al., 2017). On the other hand, someone with high sexual desire may be someone who feels difficulty controlling sexuality, but a desire for frequent sexual activity can also feel undercontrol (Carvalho et al., 2015). A minor exception was found to this general hypothesis, as results suggested that sexual drive may be a contributing factor to higher perceived compulsion for men. These results make sense, as sexual drive may reach a point that someone feels it is difficult to control (Carvalho et al., 2015; Wetterneck et al., 2012). Despite the minor exception, sexual drive was the variable most strongly associated with pornography use, and the obsessive and inhibited sexual passion variables were most consistently associated with higher perceived compulsivity.

More specifically, our second hypothesis (H2) was supported, as sexual drive was the variable most strongly associated with pornography use when all variables were evaluated simultaneously, whereas dyadic sexual desire was not associated with pornography use. It seems that sexual drive reflects a natural interest in sexuality, which may be manifest in noncompulsive engagement with pornography (Levine, 1987, 2003). Because individuals are more likely to search out forms of media with which they identify (Katz et al., 1974), our results suggest that individuals who have a higher sexual drive are more likely to search out pornography. On the other hand, although dyadic sexual desire had a positive bivariate correlation with pornography use, the association disappeared when taking all the variables in the structural equation model into account. Our data cannot provide a precise explanation why, but we can speculate. One possible reason that dyadic sexual desire was not associated with pornography use in the full structural model is that someone feeling high sexual desire for his or her partner may be more likely to pursue sexual activity with the partner rather than search out pornography. Additionally, when simultaneously evaluating dyadic sexual desire and sexual drive, sexual drive might be described as sexual interest directed toward sources other than the partner. Thus, sexual drive could be an explanation for casual pornography use, as pornography could be an outlet for sexual interest not directed at the partner. Overall, these differing associations add evidence to sexual desire's multidimensionality (Levine, 1987, 2003) by suggesting distinction between sexual drive and dyadic sexual desire. These differences should be taken into account in future research surrounding pornography.

Generally, our hypotheses for sexual passion were supported (H3a and H3b), as both obsessive and inhibited sexual passion were associated with higher perceived compulsivity, and harmonious sexual passion was associated with lower perceived compulsivity (in the bivariate correlations). However, harmonious sexual passion lost its significance in the full SEM model. This supports the understanding that sexual passion specifically addresses feelings of control surrounding sexuality (Busby et al., 2019a; Philippe et al., 2017). Particularly interesting is that both undercontrol (obsessive) and overcontrol (inhibited) were associated with higher perceived compulsivity, as both tap into different aspects of 
feeling maladaptive control. Obsessive sexual passion being related to perceived compulsivity supports previous research (Rosenberg \& Kraus, 2014). But inhibited sexual passion also being related to higher perceived compulsivity is a new finding, suggesting that maladaptive control of sexuality at either extreme could lead to reporting a lack of control surrounding pornography use. Also of note is the distinction between harmonious sexual passion and harmonious passion toward pornography which was evaluated in a previous study (Rosenberg \& Kraus, 2014). Whereas a previous study showed harmonious passion toward pornography was connected to higher pornography use and was unrelated to a reported level of sexual compulsivity (Rosenberg \& Kraus, 2014), our study suggests that harmonious sexual passion in a relationship may be a protective factor against perceived pornography compulsivity (see Table 2). But its relevance may be questioned when other factors are taken into account. Regardless, harmonious sexual passion does not seem to result in higher pornography use or perceived compulsivity. This is likely because harmonious passion includes keeping activities in balance and control with other aspects of life. Overall, this study supports the Triadic Model of Sexual Passion (Busby et al., 2019a), as it highlights sexual passion expressions distinction from sexual desire and shows that each construct of sexual passion expression is uniquely associated with perceived compulsivity.

Although the lack of measurement invariance prevented us from directly comparing models for men and women, our study still provided some interesting insights into how each gender's sexual desire and passion are connected to pornography use patterns (RQ1). For example, the combined evidence of measurement invariance tests and correlations between variables suggests that men and women conceptualize sexual desire, sexual passion expression, and pornography use patterns differently. Women have greater overlap between sexual drive and dyadic sexual desire (see Table 3 ). This measurement issue may partially explain the differences between men and women's association between sexual drive and perceived compulsivity. Perhaps men's higher discrimination between sexual drive and dyadic sexual desire comes into play here, as sensing they have a higher drive (particularly not focused on their partner) that makes them more aware and anxious about their sexual interest, making them feel as if they have less control. Though we note, this is merely conjecture and requires additional research, as our current data fail to provide an explanation for these findings. Also interesting to note is that women's dyadic sexual desire was not associated with perceived compulsivity, whereas men's dyadic sexual desire was associated with lower perceived compulsivity. However, considering the large sample size, and relatively small value of the coefficient, this association may not be practically relevant.

\section{Limitations and Future Directions}

Although the study had a number of strengths such as a large sample size, conceptual advancement of constructs, and internally consistent measurement, the study also had several limitations. The first limitation was having a convenience sample from Amazon's Mechanical Turk. Although careful screening took place to increase our confidence in the quality of participants' answers, and MTurk is often used as an appropriate avenue for exploratory analyses, it is still a non-representative sample that is more highly educated than the population. Therefore, future research should replicate findings to assess whether results are generalizable to the wider public. The second limitation was some of the measures. Although each construct showed internal consistency, conceptualization and measurement surrounding pornography, sexual desire, and sexual passion in many ways are in their infancy. Additional work is needed to validate each of the scales used. The one item measurement for the sexual desire variables is a particularly noteworthy weakness, and future work should be done to expand the constructs. A third limitation was that crosssectional data prohibited assessment of directionality. Just because we chose to conceptually focus on one direction of predictions does not preclude the possibility of alternative explanations or reversed directionality. Testing alternative models addressed this issue, as the sequence of variables could be altered and still obtain identical model fit. Many of the associations in the study are potentially bidirectional and worthy of future assessment with longitudinal data. For example, although uses and gratification theory (Katz et al., 1974) suggests that those with higher sexual drive may be more likely to seek out pornography, script theory (Gagnon \& Simon, 1973) suggests that those who more frequently view pornography may develop a higher sexual drive.

An important future direction could be to see how these variables interact with each other or explain certain associations. For example, perhaps the combination of high sexual drive and high obsessive sexual passion could be an important combination for a higher likelihood of reporting compulsive pornography use. Also, certain types of sexual desire may have a role in the development of certain types of sexual passion, which may then influence outcomes. Again, longitudinal data will be especially beneficial to parcel out the distinction of these associations. Another future direction is to further evaluate how sexual desire and sexual passion are related to other components of perceived compulsivity. Our study focused on the subjective feeling of control surrounding pornography use, as it was a component that had the strongest conceptual tie to sexual passion. However, future research could evaluate how factors such as tolerance and withdrawal from the addiction literature may be connected to both sexual desire and sexual passion. It also would be valuable to concurrently assess how sexual passion expression (Busby et al., 
2019a) in a committed relationship and passion expression particularly toward pornography (Rosenberg \& Kraus, 2014) diverge in predicting outcomes. Finally, it would be beneficial to more extensively assess how different types of sexual passion are associated with outcomes for those with a variety of sexual orientations and relationship configurations (e.g., mixed-sex versus same-sex, committed versus uncommitted, married versus dating).

As an interesting side note to the focus of our study, religiosity was not linked to perceived compulsivity to pornography either at the bivariate level or in the final SEM models. This finding goes against a consistent finding in a large body of literature, showing that religiosity is associated with the subscales for perceived addiction to pornography (e.g., Grubbs, Perry, Wilt, \& Reid, 2019; Grubbs \& Perry, 2019). Though, it should be noted that this connection has been weaker and less consistent when looking specifically at the perceived compulsivity to pornography scale and more robustly linked to emotional distress surrounding pornography (Fernandez et al., 2017). This finding does not undo the large body of research establishing the link between religiosity and perceived compulsivity to pornography, but additional data of this inconsistency may encourage researchers to further investigate the many suggested contextual factors (e.g., Grubbs, et al., 2019; Campbell \& Kohut, 2017; Leonhardt et al., 2019a; Vaillancourt-Morel, Daspe, Charbonneau-Lefebvre, \& Bosisio, 2019; Willoughby, Leonhardt, \& Augustus, 2019) in assessing when this kind of link is most likely to occur.

\section{Implications and Conclusion}

Despite limitations, this study has important implications for researchers, therapists, and pornography users. The research supports previous suggestions for the multidimensionality of sexual desire (Levine, 1987, 2003) and sexual passion (Busby et al., 2019a). Researchers should continue to examine how each of these factors interrelate and predict other outcomes in sexuality and relationship research. In particular, researchers may consider how variables in the study might moderate or mediate each other.

This study also has important implications for therapists who are working with those who report struggling with uncontrollable pornography use, and the individuals themselves who are seeking to stop. Results revealed that sexual passion is a contributor to perceived compulsion, regardless of the level of pornography use. This suggests that sexual passion expression may be one of many factors to consider in helping someone to overcome problematic pornography use. Previous research has suggested that relational factors, attachment style, sexual abuse, and personality traits are all important in the development of sexual passion (Leonhardt, Busby, \& Valdez, 2020). Therapists may consider assessing how each of those factors influence clients' sexual passion, which in turn may help them feel in control with sexuality and pornography use. This same awareness of factors has similar implications for pornography users. Those who use pornography should be mindful of their characteristics that may increase the likelihood of feeling their pornography use is uncontrollable. As mentioned previously, this study cannot fully distinguish whether the participant's perceived/reported level of compulsion reflects an actual compulsion or an inaccurate perception of the nature of their pornography use. Still, this feeling of uncontrollable use has been shown to be problematic, regardless of how often someone uses pornography (e.g., Grubbs, Stauner, Exline, \& Pargament, 2015), and it is important for therapists to be better aware of how to address this issue.

The nuanced outcomes from pornography use are a matter of heavy policy debate, as some states have declared pornography use to be a "public health crisis" (Lam, 2019). This study helps us understand some of the underlying factors that may result in approaches to pornography use. Pornography use is a heavily nuanced phenomenon, with many factors playing a role as antecedents and outcomes. This study can highlight some of the subtleties in these connections and hopefully encourage policy makers to approach this topic with nuance as well. People should be aware that maladaptive sexual passion expression may result in feeling that pornography use is uncontrollable, which can lead to negative outcomes such as depression, anxiety, and powerlessness (Butler et al., 2015; Grubbs, Stauner, Exline, \& Pargament, 2015). Meanwhile, people should also be aware of how sexual drive may lead to engaging in casual pornography use that may subtly shift expectations surrounding sexuality (Gagnon \& Simon, 1973; Gagnon, 1990). By extension, greater understanding of these results should help individuals to autonomously engage in harmoniously passionate sexual relationships.

Acknowledgements We would like to thank Dr. Sarah Coyne and Dr. Jeremy Yorgason for the helpful review of earlier drafts.

\section{References}

Bai, H. (2018). Evidence that a large amount of low quality responses on MTurk can be detected with repeated GPS coordinates. Retrieved from: https://www.maxhuibai.com/blog/evidence-that-responsesfrom-repeating-gps-are-random.

Basson, R. (2001). Human sex-response cycles. Journal of Sex \& Marital Therapy, 27, 33-43.

Basson, R. (2003). Biopsychosocial models of women's sexual response: Applications to management of "desire disorders". Sexual and Relationship Therapy, 18, 107-115.

Beach, F. A. (1956). Characteristics of masculine "sex drive". In M. R. Jones (Ed.), Nebraska symposium on motivation vol. 4 (pp. 1-32). Lincoln: University of Nebraska Press.

Bridges, A. J., Wosnitzer, R., Scharrer, E., Sun, C., \& Liberman, R. (2010). Aggression and sexual behavior in best-selling pornography 
videos: A content analysis update. Violence Against Women, 16, 1065-1085.

Brotto, L. A., Basson, R., \& Luria, M. (2008). A mindfulness-based group psychoeducational intervention targeting sexual arousal disorder in women. Journal of Sexual Medicine, 5, 1646-1659.

Brotto, L. A., \& Smith, K. B. (2014). Sexual desire and pleasure. In D. L. Tolman \& L. M. Diamond (Eds.), APA handbook of sexuality and psychology: Vol. 1. Person-based approaches (pp. 3-35). Washington, DC: American Psychological Association.

Browne, M. W. \& Cudeck, R. (1993). Alternative ways of assessing model fit. In Bollen, K.A. \& Long, J.S. (Eds.), Testing structural equation models. Newbury Park, CA: Sage, 136-162.

Buhrmester, M. D., Talaifar, S., \& Gosling, S. D. (2018). An evaluation of Amazon's Mechanical Turk, its rapid rise, and its effective use. Perspectives on Psychological Science, 13, 149-154.

Busby, D. M., Holman, T. B., \& Taniguchi, N. (2001). RELATE: Relationship evaluation of the individual, family, cultural, and couple contexts. Family Relations, 50(4), 308-316

Busby, D. M., Chiu, L. H., Leonhardt, N. D., \& Iliff, E. (2019a). Sexual passion in committed relationships: Measurement and conceptual issues. Family Process, 58, 734-748.

Busby, D. M., Leonhardt, N. D., \& James, S. (2019b). A closer look at sexual passion in relationships. Journal of Child and Family Studies. Advance online publication. https://doi.org/10.1007/s10826-01901682-4.

Busby, D. M., Willoughby, B. J., Chiu, H., \& Olsen, J. A. (2020). Measuring the multidimensional construct of pornography: A long and short version of the pornography usage measure. Archives of Sexual Behavior. Advance online publication. https://doi.org/10. 1007/s10508-020-01688-w.

Butler, M. H., Meloy, K. C., \& Call, M. L. (2015). Dismantlin powerlessness in addiction: empowering recovery through rehabilitation behavioral learning. Sexual Addiction and Compulsivity, 22(1), 26 58.

Campbell, L., \& Kohut, T. (2017). The use and effects of pornography in romantic relationships. Current Opinion in Psychology, 13, 6-10.

Carroll, J. S., Padilla-Walker, L. M., Nelson, L. J., Olson, C. D., Barry, C., \& Madsen, S. D. (2008). Generation XXX: Pornography acceptance and use among emerging adults. Journal of Adolescent Research, 23, 6-30.

Carvalho, J., Štulhofer, A., Vieiera, A. L., \& Jurin, T. (2015). Hypersexuality and high sexual desire: exploring the structure of problematic sexuality. Journal of Sexual Medicine, 12(6), 13561367.

Chmielewski, M., \& Kucker, S. C. (2019). An MTurk crisis? Shifts in data quality and the impact on study results. Social Psychological and Personality Science. Advance online publication, 11, 464-473. https://doi.org/10.1177/1948550619875149.

Cooper, A., Delmonico, D., \& Burg, R. (2000). Cybersex users, abusers, and compulsives: New findings and implications. Sexual Addiction \& Compulsivity, 7(1-2), 5-29.

Cooper, A., Morahan-Martin, J., Mathy, R. M., \& Maheu, M. (2002). Toward an increased understanding of user demographics in online sexual activities. Journal of Sex \& Marital Therapy, 28, 105-129.

Cooper, A., Scherer, C. R., Boies, S. C., \& Gordon, B. L. (1999). Sexuality on the internet: From sexual exploration to pathological expression. Professional Psychology: Research and Practice, 30 , 154-164.

Coplan, R. J., Prakash, K., O’Neil, K., \& Armer, M. (2004). Do you 'want' to play? Distinguishing between conflicted-shyness and social disinterest in early childhood. Developmental Psychology, 40, 244-258.

Fernandez, D. P., Tee, E. Y. J., \& Fernandez, E. F. (2017). Do cyber pornography use inventory-9 scores reflect actual compulsivity in internet pornography use? Exploring the role of abstinence effort. Sexual Addiction and Compulsivity, 24, 156-179.
Gagnon, J. H. (1990). The explicit and implicit use of the scripting perspective in sex research. Annual Review of Sex Research, 1, 1-43.

Gagnon, J. H., \& Simon, W. (1973). Sexual conduct: The social sources of human sexuality. Chicago: Aldine Books.

Gola, M., Lewczuk, K., \& Skorko, M. (2016). What matters: Quantity or quality of pornography use? Psychological and behavioral factors of seeking treatment for problematic pornography use. Journal of Sexual Medicine, 13, 815-824.

Grubbs, J. B., Exline, J. J., \& Pargament, K. I. (2015). Internet pornography use: Perceived addiction, psychological distress, and the validation of a brief measure. Journal of Sex \& Marital Therapy, 41, 83-106.

Grubbs, J. B., Exline, J. J., Pargament, K. I., Hook, J. N., \& Carlisle, R. D. (2015). Transgression as addiction: Religiosity and moral disapproval as predictors of perceived addiction to pornography. Archives of Sexual Behavior, 44, 125-136.

Grubbs, J. B., Kraus, S. W., \& Perry, S. L. (2019). Self-reported addiction to pornography in a nationally representative sample: The role of religiousness and morality. Journal of Behavioral Addictions, 8, 8893.

Grubbs, J. B., \& Perry, S. L. (2019). Moral incongruence and pornography use: A critical review and integration. Journal of Sex Research, 56, 29-37.

Grubbs, J. B., Perry, S. L., Wilt, J. A., \& Reid, R. C. (2019). Pornography problems due to moral incongruence: An integrative model with a systematic review and meta-analysis. Archives of Sexual Behavior, 48, 397-414.

Grubbs, J. B., Stauner, N., Exline, J. J., \& Pargament, K. I. (2015). Perceived addiction to internet pornography and psychological distress: Examining relationships concurrently and over time. Psychology of Addictive Behaviors, 29, 1056-1067. https://doi. org/10.1037/adb0000114.

Hatfield, E. \& Rapson, R. L. (1990). Passionate love in intimate relations. In B. S. Moore \& A. Isen (Eds.), Affect and social behavior (pp. 126-152). Cambridge: Cambridge University Press.

Katz, E., Blumler, J. G., \& Gurevitch, M. (1974). Utilization of mass communication by the individual. In J. G. Blumler \& E. Katz (Eds.), The uses of mass communication: Current perspectives on gratifications research (pp. 19-32). Beverly Hills: Sage.

Kline, R. B. (2016). Principles and practice of structural equation modeling. New York City: Guilford Press.

Klusmann, D. (2002). Sexual motivation and the duration of partnership. Archives of Sexual Behavior, 31, 275-287.

Kohut, T., Balzarini, R. N., Fisher, W. A., Grubbs, J. B., Campbell, L., \& Prause, N. (2019). Surveying pornography use: A shaky science resting on poor measurement foundations. Journal of Sex Research. Advance online publication. https://doi.org/10.1080/ 00224499.2019 .1695244$.

Lafreniere, M. A. K., Jowett, S., Vallerand, R. J., Donahue, E. G., \& Lorimer, R. (2008). Passion in sport: On the quality of the coachplayer relationship. Journal of Sport and Exercise Psychology, $30(5), 541-560$.

Lam, K. (2019). States call pornography a public health crisis; Porn industry decries 'fear mongering.' USA Today. Retrieved from https://www.usatoday.com/story/news/nation/2019/05/09/ pornography-public-health-crisis-states-adopt-measures-againstporn/1159001001/

Laumann, E. O., Paik, A., \& Rosen, R. C. (1999). Sexual dysfunction in the United States: Prevalence and predictors. JAMA, 281, 537-544.

Leonhardt, N. D., Busby, D. M., \& Valdez, C. (2020). Pursuit of harmony: relational and individual predictors of sexual passion expression. Archives of Sexual Behavior. Advance online publication. https:// doi.org/10.1007/s10508-020-01769-w.

Leonhardt, N. D., Spencer, T. J., Butler, M. H., \& Theobald, A. C. (2019a). An organizational framework for sexual media's influence 
on short-term versus long-term sexual quality. Archives of Sexual Behavior, 48, 2233-2249.

Leonhardt, N. D., Spencer, T. J., Butler, M. H., \& Theobald, A. C. (2019b). Sexual media and sexual quality: Aims, distinctions, and reflexivity-Response to commentaries. Archives of Sexual Behavior, 48, 2291-2303.

Leonhardt, N. D., \& Willoughby, B. J. (2019). Pornography, provocative sexual media, and their differing associations with multiple aspects of sexual satisfaction. Journal of Social and Personal Relationships, $36,618-641$.

Leonhardt, N. D., Willoughby, B. J., \& Young-Petersen, B. (2018). Damaged goods: Perception of pornography addiction as a mediator between religiosity and relationship anxiety surrounding pornography use. Journal of Sex Research, 55(3), 357-368.

Levine, S. B. (1987). More on the nature of sexual desire. Journal of Sex \& Marital Therapy, 13(1), 35-44.

Levine, S. B. (2003). The nature of sexual desire: A clinician's perspective. Archives of Sexual Behavior, 32(3), 279-285.

Luster, S. S., Nelson, L. J., Poulsen, F. O., \& Willoughby, B. J. (2013). Emerging adult sexual attitudes and behaviors: Does shyness matter? Emerging Adulthood, 1, 185-195.

MacDonald, K., \& Feifel, D. (2012). Dramatic improvement in sexual function induced by intranasal oxytocin. Journal of Sexual Medicine, 9, 1407-1410.

Masters, W. H., \& Johnson, V. E. (1966). Human sexual response. Boston: Little, Brown

McCarthy, B., \& McDonald, D. (2009). Assessment, treatment, and relapse prevention: Male hypoactive sexual desire disorder. Journal of Sex \& Marital Therapy, 35, 58-67.

Meston, C., Gorzalka, B. B., \& Wright, J. M. (1997). Inhibition of subjective and physiological sexual arousal in women by clonidine. Psychosomatic Medicine, 59, 399-407.

Muthen, L. K., \& Muthen, B. O. (1998-2012). MPlus user's guide. 7th. Los Angeles: Muthen \& Muthen.

Nobre, P. J. (2009). Determinants of sexual desire problems in women: Testing a cognitive-emotional model. Journal of Sex \& Marital Therapy, 35(5), 360-377.

Novak, S. P., \& Clayton, R. R. (2001). The influence of school environment and self-regulation on transitions between stages of cigarette smoking: A multilevel analysis. Health Psychology, 20, 196-207.

Olmstead, S. B., Negash, S., Pasley, K., \& Fincham, F. D. (2013). Emerging adults' expectations for pornography use in the context of future committed romantic relationships: a qualitative study. Archives of Sexual Behavior, 42, 625-635.

Paolacci, G., Chandler, J., \& Ipeirotis, P. G. (2010). Running experiments on Amazon Mechanical Turk. Judgment and Decision making, 5, 411-419.

Pfaus, J. G. (2009). Pathways of sexual desire. Journal of Sexual Medicine, 6, 1506-1533.

Philippe, F. L., Vallerand, R. J., Bernard-Desrosiers, L., Guilbault, V., \& Rojotte, G. (2017). Understanding the cognitive and motivational underpinnings of sexual passion from a dualistic model. Journal of Personality and Social Psychology, 113(5), 769-785.

Prause, N., \& Pfaus, J. (2015). Viewing sexual stimuli associated with greater sexual responsiveness, not erectile dysfunction. Journal of Sexual Medicine, 3(2), 90-98.

Regnerus, M. D., Gordon, D., \& Price, J. (2016). Documenting pornography use in America: A comparative analysis of methodological approaches. Journal of Sex Research, 53, 873-881.

Rosenberg, H., \& Kraus, S. (2014). The relationship of "passionate attachment" for pornography with sexual compulsivity, frequency of use, and craving for pornography. Addictive Behaviors, 39(5), 1012-1017.

Steele, V. R., Staley, C., Fong, T., \& Prause, N. (2013). Sexual desire, not hypersexuality, is related to neurophysiological responses elicited by sexual images. Socioaffective Neuroscience and Psychology, 3, 20770.

Sternberg, R. J. (1986). A triangular theory of love. Psychological Review, 93(2), 119-135.

Suri, S., \& Watts, D. J. (2011). Cooperation and contagion in web-based, networked public goods experiments. PLoS One, 8356, e16836.

Sussman, S., Lisha, N., \& Griffiths, M. (2011). Prevalence of the addictions: A problem of the majority or the minority? Evaluation Health Professional, 34(1), 3-56.

Vaillancourt-Morel, M. P., Daspe, M. E., Charbonneau-Lefebvre, V., \& Bosisio, M. (2019). Pornography use in adult mixed-sex romantic relationships: Context and correlates. Current Sexual Health Reports, 11, 35-43.

Vallerand, R. J., Mageau, G. A., Ratelle, C., Leonard, M., Blanchard, C., Koestner, R., Gagne, M., \& Marsolaid, J. (2003). Les passions de l'Ame: On obsessive and harmonious passion. Journal of Personality and Social Psychology, 85, 756-767.

Vandenbosch, L., \& Eggermont, S. (2012). Understanding sexual objectification: A comprehensive approach toward media exposure and girls' internalization of beauty ideals, self-objectification, and body surveillance. Journal of Communication, 62, 869-887.

Wetterneck, C. T., Burgess, A. J., Short, M. B., Smith, A. H., \& Cervantes, M. E. (2012). The role of sexual compulsivity, impulsivity, and experiential avoidance in internet pornography use. The Psychological Record, 62, 3-18.

Willoughby, B., Leonhardt, N., \& Augustus, R. (2019). Untangling the porn web: Creating an organizing framework for pornography research among couples. Journal of Sex Research. Advance online publication., 1-13. https://doi.org/10.1080/00224499.2019. 1698003.

Willoughby, B. J., \& Busby, D. M. (2016). In the eye of the beholder: Exploring variations in the perception of pornography. The Journal of Sex Research, 53, 678-688.

Publisher's Note Springer Nature remains neutral with regard to jurisdictional claims in published maps and institutional affiliations. 